\title{
USE OF CONTINUOUS GLUCOSE MONITORING (CGM) TECHNOLOGY IN THE MANAGEMENT OF TYPE 2 DIABETES MELLITUS IN THE PRIMARY CARE SETTING: A CASE REPORT
}

Dr Teo Cheng Rong

\begin{abstract}
This case report of a 30-year-old type 2 diabetic patient illustrates the advantages of using real-time continuous glucose monitoring (rt-CGM) in a primary care setting. The patient was successfully weaned off subcutaneous insulin injections over a period of two months and achieved even better time-in-range outcomes. The patient is empowered with more insight into his metabolic condition and is currently trying new techniques such as intermittent fasting to further improve his diabetes.
\end{abstract}

Key Words: Diabetes mellitus, continuous glucose monitoring, time in range, HbAl c, primary care

\section{CASE:}

$\mathrm{Mr} \mathrm{E}$ is a 30-year-old gentleman from the Philippines who presented to the clinic in January 2020 for a continuation of care for his type 2 diabetes mellitus. He is a non-smoker and works as a financial consultant.

Mr E has a strong family history of type 2 diabetes mellitus and a BMI of 40 at the point of diagnosis contributed by high consumption of energy drinks and his sedentary lifestyle. He was diagnosed with type 2 diabetes mellitus in October 2015 when he presented with loss of weight, lethargy, polydipsia and polyuria. His fasting blood glucose then was $18.18 \mathrm{mmol} / \mathrm{L}$.

He was initially started on Metformin Extended-Release $1000 \mathrm{mg} \mathrm{BD}$ and glimepiride $2 \mathrm{mg}$ after breakfast but was switched out of metformin due to concerns of transaminitis (AST $102 \mathrm{U} / \mathrm{L}$ and ALT $182 \mathrm{U} / \mathrm{L}$ ) to subcutaneous basal insulin (glargine) injection at $10 \mathrm{IU}$. This was slowly up titrated to 30 IU before he moved to Singapore in 2017 and he has maintained at the same dosage since.

On his first visit to the clinic, Mr E was still overweight with a $\mathrm{BMI}$ of 38. His physical examination was unremarkable. $\mathrm{Mr}$ E was on $30 \mathrm{IU}$ of glargine insulin (OM/pre-breakfast) and glimepiride $2 \mathrm{mg}$ (ON/pre-dinner). Baseline investigations

\section{DR TEO CHENG RONG}

Anchor Doctor

Healthway Medical Group, Choa Chu Kang Limbang Branch performed in February 2020 revealed a HbA1c of 5.5 percent, with normal renal function, mild transaminitis (AST $43 \mathrm{U} / \mathrm{L}$ and AST $55 \mathrm{U} / \mathrm{L}$ ) and no microalbuminuria.

The concept of CGM was first introduced to the patient in April 2020, and he was receptive to the idea. We used the Abbott Freestyle Libre flash glucose monitoring system. The system has three systems: a disposable sensor, a handheld reader (mobile phone with near field communication technology), and associated software. The sensor is applied to the upper arm of the patient and activated using the reader. The sensor is worn by the patient for up to 14 days, over which time it records interstitial glucose readings every minute. The patient will require to scan using his phone at least once every eight hours. Data of glucose readings will be automatically uploaded onto the Freestyle Libre ${ }^{\mathrm{TM}}$ application as well as Libreview ${ }^{\mathrm{TM}}$ where the physician can $\log$ in to view the real-time glucose patterns, including hypoglycaemia, hyperglycaemia, time in range and glycaemic variation.

Diagram 1 is the timeline illustrating the progress of Mr E's diabetic treatment. Figure 1 shows the CGM readings over one week in the months of April, June and July 2020. Table 1 summarises the changes in parameters and treatment regimens over these three months. 
Figure I: One-week CGM readings in months of April, June and July 2020

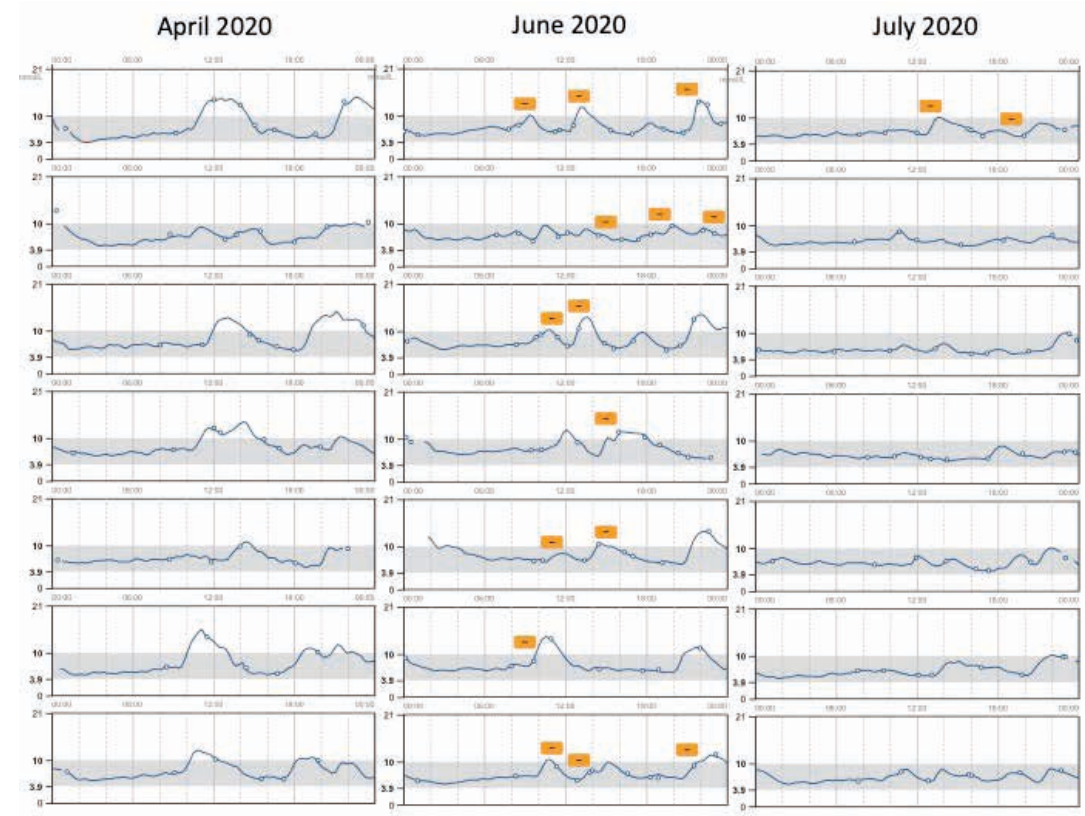

Table I: Changes in parameters and treatment regimens for Mr E

\begin{tabular}{|l|l|l|l|}
\hline \multicolumn{1}{|c|}{ Parameters } & \multicolumn{1}{c|}{ April 2020 } & \multicolumn{1}{c|}{ June 2020 } & \multicolumn{1}{c|}{ July 2020 } \\
\hline HbA1c & 5.5 & - & 6.1 \\
\hline Time in Range/\% & 82 & 89 & 99 \\
\hline Hypoglycaemic event(s)/\% & 1 & 0 & 0 \\
\hline Weight/kg & 116 & 112 & 110 \\
\hline Treatment & $\begin{array}{l}30 \text { IU Glargine every } \\
\text { morning } \\
2 \text { mg Glimepiride every } \\
\text { morning }\end{array}$ & - & $\begin{array}{l}\text { Dapagliflozin } 10 \mathrm{mg} / \\
\text { Metformin 2000 mg daily } \\
\text { (two tablets of Xig-duo } \\
5 / 1000) \text { every morning }\end{array}$ \\
\hline
\end{tabular}

In April 2020, we first noticed huge fluctuations in preand post-prandial sugar readings. There was one percent of hypoglycaemic events, and the time in range was 82 percent. No adjustment to medications was made.

In June 2020, we decided to initiate SGLT-2 inhibitor treatment using dapagliflozin $10 \mathrm{mg}$ with the hope of reducing insulin requirement and achieving weight loss for the patient. As he was on subcutaneous insulin, there were concerns of hypoglycaemia with overtreatment and hyperglycaemia if insulin was cut down too quickly. Fortunately, the problem was easily overcome by the use of CGM and an online platform (Libreview ${ }^{\mathrm{TM}}$ ) for the physician to view the real-time data of the patient's glucose readings. Instructions were communicated via messaging application (WhatsApp) to down titrate the insulin over the course of one week to a lowest of 15 IU. During this period, the time in range improved to 89 percent. Insulin requirements were eventually adjusted to $20 \mathrm{IU} /$ day.

Encouraged by these positive results, Mr E expressed the desire to be taken off insulin injection, if possible. Analysing and comparing the graphs of his glucose excursions between April and June 2020, it was noted that Mr E's baseline glucose readings and duration of post-prandial hyperglycaemia were brought down, most likely from the glucosuric effects of dapagliflozin and lifestyle modifications such as restriction and dietary adjustments in carbohydrates. Since the latest liver enzymes were normal, we decided to reintroduce metformin in his diabetic regime with the hope to lower his insulin requirements further. True enough, his mealtime glucose curves flattened, and he was able to stop insulin completely about one week into the introduction of two grams of metformin together with $10 \mathrm{mg}$ of dapagliflozin. By the end of July 2020 (approximately three months from the introduction of CGM), $\mathrm{Mr} \mathrm{E}$ achieved a time in range of 99 percent, and ideal HbAlc of 6.1 percent with no significant rise in liver enzymes (AST $31 \mathrm{U} / \mathrm{L}$ and ALT 60 U/L) two weeks from initiation of metformin.

The patient is thankful for being insulin-free and has embarked on more intensive lifestyle modifications such as intermittent fasting. He will be monitoring the effects of fasting using the CGM method again. 


\section{DISCUSSION:}

This case study illustrates the use of CGM technology in reversing the use of insulin in a type 2 diabetes patient. The factors that allow the optimal use of CGM in this case are 1. Patient's high education level, 2. High self-motivation 3. Use of technology to assist in effective communication between the physician and patient, 4. Affordability of the CGM device. After putting on the CGM device, it has broadened the patient's vision of his metabolic condition: it managed to pick up a one percent duration of hypoglycaemic events that were unrecognised clinically while the patient was still on insulin injections (April 2020), the patient was more aware of how his diet and exercise impacted the diurnal variations in glucose readings as well as it promoted patient's autonomy in the decision-making process for management of diabetes. There is so far one prospective trial in Japan that demonstrated the effectiveness of Freestyle Libre ${ }^{\mathrm{TM}}$ CGM at improving glycaemic control in Japanese type 2 diabetes treated with insulin. ${ }^{1}$ Indices of glycaemic control, including time in range, mean glucose and time in hyperglycaemia, were significantly improved. However, the mean total daily dose of insulin was unchanged at the study end. It is therefore interesting to note that we managed to down titrate and wean $\mathrm{Mr} \mathrm{E}$ off insulin injection in a short duration of two months. The possible reasons could be his relatively young age, short duration of disease (five years) and the presence of reasonable endogenous insulin reserves.

Another concept that was introduced to the patient by the implementation of CGM was Time in Range (TiR). TiR is a relatively new parameter in the management of diabetes mellitus and is defined as the percentage of time spent in the target range between 70 and $180 \mathrm{mg} / \mathrm{dL}$ (or 3.9 and $10 \mathrm{mmol} / \mathrm{L}$ ) while reducing time in hypoglycaemia. ${ }^{2}$ The Advanced Technologies and Treatments for Diabetes (ATTD) consensus panel has identified it as a metric of glycaemic control that provides more actionable information than HbA1c alone. ${ }^{3}$ Initial studies have shown a linear inverse relationship between $\mathrm{HbA1c}$ and $\mathrm{TiR}$ in which for every absolute ten percent change in $\mathrm{TiR}$, there was a 0.8 percent change in HbAlc. ${ }^{4}$ However, in this case report, we demonstrated that the patient initially has a "better" $\mathrm{HbA1c}$ of 5.5 percent but a poorer TiR of 82 percent in April 2020. At the end of July 2020, even though the HbA1c has slightly risen to 6.1 percent (+0.6percent), the TiR improved to 99 percent $(+17$ percent). This shows that HbA1c may not necessarily correlate well with TiR, especially when the patient's $\mathrm{HbAlc}$ is already in the ideal range. Further studies have also recognised the poor correlation between these two parameters. It was found that for a specified $\mathrm{TiR}$, there was a wide range of possible HBAIC levels which is apparent when observing a graph of TiR versus HbA1c. ${ }^{5}$ As such, there should be more awareness in the use of CGM to help identify patients whose HbAlc may be ideal but fall short in the TiR target. This might have a positive impact on our diabetic care management because there are an increasing number of studies linking better TiR with lower rates of complications such as diabetic retinopathy ${ }^{6,7}$, peripheral neuropathy ${ }^{8,9}$ and carotid intima thickness. ${ }^{10}$

Technological advances in CGM opened up more windows of opportunity for coordination of care between physicians and patients in the primary care setting. Only a few years ago, patients were required to purchase a separate device to scan for glucose readings. Currently, they just require to download the application on their mobile phones (with near field communication technology) and can use their phones as scanning devices. Not only does this improve convenience, but it also lowers the overall costs of using CGM. With the integration of other applications such as LibreLinkUp ${ }^{\mathrm{TM}}$ and Libreview ${ }^{\mathrm{TM}}$ (part of the Freestyle Libre ${ }^{\mathrm{TM}}$ system), physicians can be sent notifications when patients transmit their glucose data and readily log in to their linked accounts to view the glucose graphs of their patients. This allows physicians to interpret real-time data and provide timely advice or modifications to their prescription of diabetic medications. This revolutionises the way how diabetes can be treated in the primary care setting and hopefully achieves better clinical outcomes. Though the evidence of CGM in the treatment of type 1 diabetes mellitus appears strong, the role of CGM in type 2 diabetes in the primary care setting appears less robust. ${ }^{11}$ In a most recent randomised controlled trial (GP-OSMOTIC) to determine the use of retrospective CGM ( $r-C G M)$ in adults with type 2 diabetes in general practice $^{12}$, this Australian study found no improvement in HbA1c at 12 months or diabetes-specific distress compared with usual care. But they did find that CGM can improve TiR at 12 months and HbAlc at six months. They conclude that the improved TiR might reflect the potential of the technology to support personalised clinical care for some people with type 2 diabetes. Future studies are needed to evaluate the potential of real-time CGM, coupled with new technological advances, in improving diabetes care in primary care.

\section{REFERENCES:}

I. Ogawa W, Hirota Y, Osonoi T, Tosaki T, Kato Y, Utsunomiya K, Nishimura R, Nakamura J. Effect of the FreeStyle Libre ${ }^{T M}$ flash glucose monitoring system on glycemic control in individuals with type 2 diabetes treated with basal-bolus insulin therapy: An open label, prospective, multicenter trial in Japan. [published online ahead of print, 2020 Jun 19]. J Diabetes Investig. 2020;10.1III/ jdi. I3327. doi: I0. I I I I/jdi. I 3327

2. Gabbay MA, Rodacki M, Calliari LE, Vianna AG, Krakauer M, Pinto MS, Reis JS, Puñales M, Miranda LG, Ramalho AC, Franco DR. Time in range: a new parameter to evaluate blood glucose control in patients with diabetes. Diabetology \& Metabolic Syndrome. 2020 Dec; I 2(I): I-8.

3. Battelino T, Danne T, Bergenstal RM, Amiel SA, Beck R, Biester T, Bosi E, Buckingham BA, Cefalu WT, Close KL, Cobelli C. Clinical targets for continuous glucose monitoring data interpretation: recommendations from the international consensus on time in range. Diabetes Care. 2019 Aug I;42(8):I593-603.

4. Vigersky RA, McMahon C. The relationship of hemoglobin AIC to time-in-range in patients with diabetes. Diabetes technology \& therapeutics. 2019 Feb I;2I(2):8I-5.

5. Beck RW, Bergenstal RM, Cheng P, Kollman C, Carlson AL, Johnson ML, Rodbard D. The relationships between time in range, hyperglycemia metrics, and HbAlc. Journal of diabetes science 
and technology. 2019 Jul; I3(4):614-26.

6. Lu J, Ma X, Zhou J, Zhang L, Mo Y, Ying L, Lu W, Zhu W, Bao Y, Vigersky RA, Jia W. Association of time in range, as assessed by continuous glucose monitoring, with diabetic retinopathy in type 2 diabetes. Diabetes Care. 2018 Nov I;4I(I I):2370-6.

7. Beck RW, Bergenstal RM, Riddlesworth TD, Kollman C, Li Z, Brown $\mathrm{AS}, \mathrm{Close} \mathrm{KL}$. Validation of time in range as an outcome measure for diabetes clinical trials. Diabetes Care. 2019 Mar I;42(3):400-5.

8. Mayeda L, Katz R, Ahmad I, Bansal N, Batacchi Z, Hirsch IB, Robinson N, Trence DL, Zelnick L, de Boer IH. Glucose time in range and peripheral neuropathy in type 2 diabetes mellitus and chronic kidney disease. BMJ Open Diabetes Research and Care. 2020 Jan I;8(I).

9. Yang J, Yang X, Zhao D, Wang X, Wei W, Yuan H. Association of time in range, as assessed by continuous glucose monitoring, with painful diabetic polyneuropathy. Journal of Diabetes Investigation. 2020 Sep 3.
10. Lu J, Ma X, Shen Y, Wu Q, Wang R, Zhang L, Mo Y, Lu W, Zhu $W$, Bao Y, Vigersky RA. Time in range is associated with carotid intima-media thickness in type 2 diabetes. Diabetes Technology \& Therapeutics. 2020 Feb I;22(2):72-8.

II. Wood A, O'Neal D, Furler J, Ekinci El. Continuous glucose monitoring: a review of the evidence, opportunities for future use and ongoing challenges. Internal medicine journal. 2018 May;48(5):499-508.

12. Furler J, O'Neal D, Speight J, Blackberry I, Manski-Nankervis JA, Thuraisingam S, de La Rue K, Ginnivan L, Doyle R, HolmesTruscott E, Khunti K. Use of professional-mode flash glucose monitoring, at 3-month intervals, in adults with type 2 diabetes in general practice (GP-OSMOTIC): a pragmatic, open-label, 12-month, randomised controlled trial. The Lancet Diabetes \& Endocrinology. 2020 Jan I;8(I):17-26.

\section{LEARNING POINTS}

- CGM technology is an efficient and effective tool to complement diabetic management, especially in a primary care clinic. However, physicians do need to consider patients' factors when choosing CGM for their patients.

- TiR is a new parameter that provides critical information about diabetes control. Improvement in TiR is associated with lower microvascular and macrovascular complications.

- Newer technology enables real-time CGM and interpretation of data, with the potential of translating to better clinical outcomes for diabetes patients. 